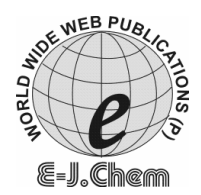

http://www.e-journals.net
ISSN: 0973-4945; CODEN ECJHAO

E-Journal of Chemistry 2010, 7(3), 827-832

\title{
Validated RP-HPLC Method for Analysis of Aripiprazole in a Formulation
}

\author{
R. KALAICHELVI*, B. THANGABALAN ${ }^{\S}$ and D. SRINIVASA RAO \\ K.C.Reddy Institute of Pharmaceutical Sciences, \\ Jangamguntla Palem, Medikonduru Mandal, Guntur-522 348, India. \\ ${ }^{\S}$ SIMS College of Pharmacy, Mangaldas Nagar, Guntur-522 001, India. \\ rkselvi123@rediffmail.com
}

Received 31 October 2009; Accepted 20 December 2009

\begin{abstract}
A rapid, simple and validated reversed-phase high-performance liquid chromatographic method has been developed for analysis of aripiprazole in tablet dosage form. Aripiprazole was separated on an ODS analytical column with a 40:60 (v/v) mixture of acetonitrile and triethanolamine buffer $(5 \mathrm{mM}, \mathrm{pH} 3.5 \pm 0.05$ adjusted by addition of $85 \%$ phosphoric acid) as mobile phase at a flow rate of $1.5 \mathrm{~mL} \mathrm{~min}^{-1}$. The effluent was monitored by UV detection at $254 \mathrm{~nm}$. Calibration plots were linear in the range of 20 to $60 \mu \mathrm{g} \mathrm{mL}^{-1}$ and the LOD and LOQ were 0.411 and $1.248 \mu \mathrm{g} \mathrm{mL}^{-1}$, respectively. The high recovery and low relative standard deviation confirm the suitability of the method for routine quality control determination of aripiprazole in tablets.
\end{abstract}

Keywords: Aripiprazole, RP-HPLC, Tablet analysis, Validation.

\section{Introduction}

Aripiprazole, (7-[4-[4-(2, 3-dichlorophenyl)-1-piperazinyl] butoxy]-3, 4-dihydrocarbostyril (Figure 1), is a psychotropic agent belonging to the chemical class of benzisoxazole derivatives and is indicated for the treatment of schizophrenia ${ }^{1,2}$. In the references, gas chromatography-mass spectrometry ${ }^{3}, \mathrm{LC}_{-\mathrm{MS} / \mathrm{MS}^{4}}$, capillary electrophoresis ${ }^{6}$, methods are reported for the analysis of aripiprazole in biological fluids. HPLC is the technique that most commonly used for the determination of aripiprazole in plasma ${ }^{5-9}$, UPLC-MS in in vitro samples ${ }^{10}$ and RP-HPLC method in bulk drug and solid dosage forms by internal standard method $^{11}$ also reported. In this paper we describe a simple, accurate, sensitive and validated RP-HPLC method for analysis of aripiprazole in tablet formulation. This method has been successfully used for quality-control analysis of drugs and for other analytical purposes. 


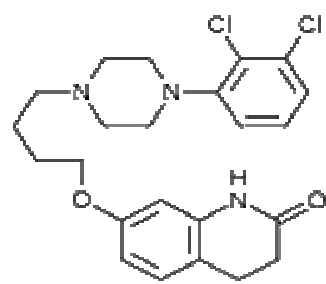

Figure 1. The structure of aripiprazole.

\section{Experimental}

A reference standard of aripiprazole was obtained from Orchid Healthcare (Chennai, India). A pharmaceutical product containing the same drug $(30 \mathrm{mg}$ per tablet), obtained from the same laboratory and was used in the experiments. Acetonitrile (HPLC grade; ACN) and water of HPLC grade were from Qualigens (Bombay, India) and orthophosphoric acid and triethanolamine (analytical reagent grade) were purchased from SD Fine Chemicals (Bombay, India). De-ionized water was used throughout the experiment. Before use, mobile phase was filtered through a $0.45 \mu \mathrm{m}$ cellulose acetate filter from Millipore (USA). Whatman no. 41 filter papers (obtained commercially) were used for preparation of sample solutions.

\section{Chromatographic system and conditions}

Analysis was performed with a Shimadzu (Japan) chromatograph comprising an LC-10 AT VP solvent-delivery module, a SPD-10A UV-visible detector, $10 \mu \mathrm{L}$ sample loop. Aripiprazole was chromatographed on a $250 \mathrm{~mm} \times 4.6 \mathrm{~mm}$ i.d., $5 \mu \mathrm{m}$ particle, Hypersil Gold ODS analytical column under reversed-phase partition conditions. The mobile phase was a 40: $60(\mathrm{v} / \mathrm{v})$ mixture of acetonitrile and triethanolamine buffer $(5 \mathrm{mM}, \mathrm{pH} 3.5 \pm 0.05$, adjusted by addition of $85 \%$ phosphoric acid). The flow rate was $1.5 \mathrm{~mL} \mathrm{~min}^{-1}$ and the analyte was monitored at $254 \mathrm{~nm}$. The system was used in an air-conditioned HPLC laboratory $\left(20 \pm 2{ }^{\circ} \mathrm{C}\right)$. Before analysis the mobile phase was degassed by use of a Branson Ultrasonics (USA) sonicator and filtered through a $0.2 \mu \mathrm{m}$ injection filter. The column was equilibrated before each injection.

\section{Calibration}

Calibration plots were constructed by analysis of appropriate working solutions (concentration 20,30, 40, 50 and $60 \mu \mathrm{g} \mathrm{mL}^{-1}$ ) of aripiprazole in the mobile phase and plotting concentration against peak-area response for each injection. Unknown samples were quantified by reference to these calibration plots.

\section{Sample preparation}

Twenty tablets were weighed and powdered. An amount of powder equivalent to $50 \mathrm{mg}$ aripiprazole was accurately weighed and transferred to a $50 \mathrm{~mL}$ volumetric flask. Mobile phase $(25 \mathrm{~mL})$ was added and the mixture was sonicated for $10 \mathrm{~min}$ for complete extraction of the drug and the solution was diluted to volume with mobile phase. The solution was centrifuged at $4000 \mathrm{rpm}$ for $10 \mathrm{~min}$ and the clear supernatant was collected and filtered through a $0.2 \mu \mathrm{m}$ membrane filter. From this solution $2 \mathrm{~mL}$ was taken and diluted to $50 \mathrm{~mL}$ with mobile phase, to furnish a $40 \mu \mathrm{g} \mathrm{mL}^{-1}$ solution, of which $10 \mu \mathrm{L}$ was injected for HPLC analysis.

\section{Statistical calculations}

Standard regression curve analysis was performed by use of Microsoft (USA) Office Excel 2003 software, without forcing through zero. Means and standard deviations were calculated by use of SPSS software version 9.5 (SPSS, Cary, NC, USA). Homoscedasticity for the calibration plots was tested by using GraphPad Prism software, demo version. 


\section{Results and Discussion}

\section{Method development and optimization}

Column chemistry, solvent selectivity (solvent type), solvent strength (volume fraction of organic solvent(s) in the mobile phase), additive strength, detection wavelength and flow rate were varied to determine the chromatographic conditions giving the best separation. The mobile phase conditions were optimized, so there was no interference with the aripiprazole peak from solvent or excipient peaks. Other criteria, for example the time required for analysis, assay sensitivity, solvent noise and use of the same solvent system for extraction of the drug from formulation matrices during drug analysis, were also considered. After each change of mobile phase the column was equilibrated by passage of at least twenty column volumes of the new mobile phase. To investigate the appropriate wavelength for determination of aripiprazole, UV-visible spectra in the range $200-400 \mathrm{~nm}$ were acquired from a solution of the drug in the mobile phase (Elico, India; model SL-164 spectrophotometer). From the UV spectra obtained the wavelength selected for monitoring the drug was $254 \mathrm{~nm}$. Solutions of the drug in the mobile phase were injected directly for HPLC analysis and the responses (peak area) were recorded at $254 \mathrm{~nm}$. It was observed there was no interference from the mobile phase or baseline disturbance at $254 \mathrm{~nm}$. Therefore, it was, concluded that $254 \mathrm{~nm}$ was the most appropriate wavelength for analysis of the substance with suitable sensitivity.

\section{Chromatography}

Symmetrical peaks were obtained for aripiprazole. Typical chromatograms obtained from a blank and from a solution of the drug are illustrated in Figure 2(a\&b). The retention time of aripiprazole was $3.8 \mathrm{~min}$ and the overall chromatographic run time was $8.0 \mathrm{~min}$.

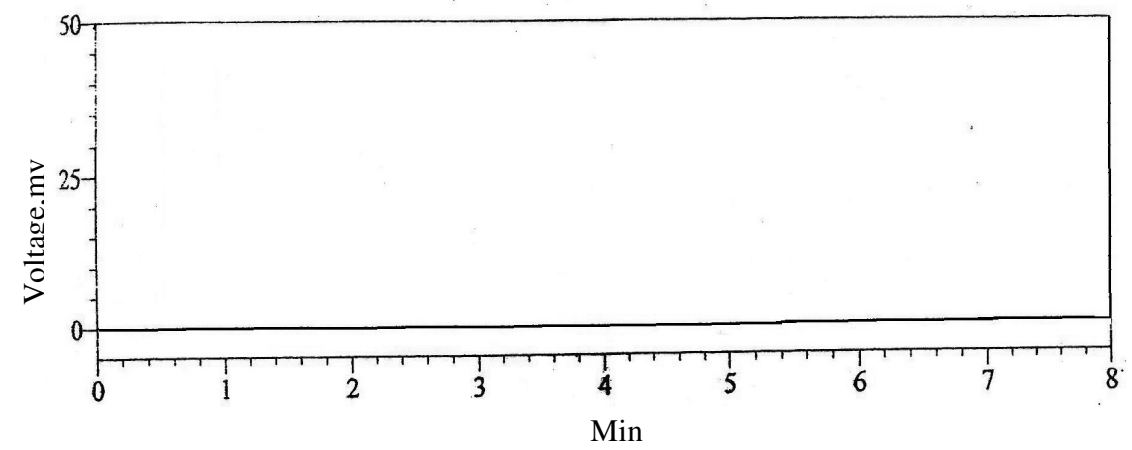

Figure 2(a)

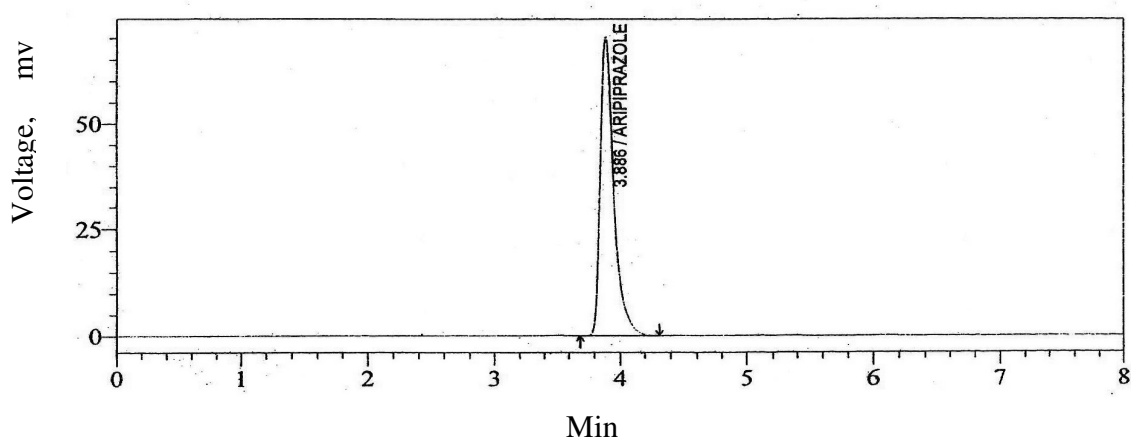

Figure 2(b)

Figure 2. (a) Typical chromatograms obtained from blank and (b) aripiprazole solution. 
Method Validation ${ }^{12-15}$

\section{Linearity}

The linearity of the method was tested using the calibration solutions described above. Plot of concentrations against responses were linear in the range of $20-60 \mu \mathrm{g} \mathrm{mL}^{-1}$ (Figure 3). The mean regression equation was $Y=1.2958 \times 10^{4} \mathrm{x}+1422.2$. The correlation coefficient was 0.9999 .

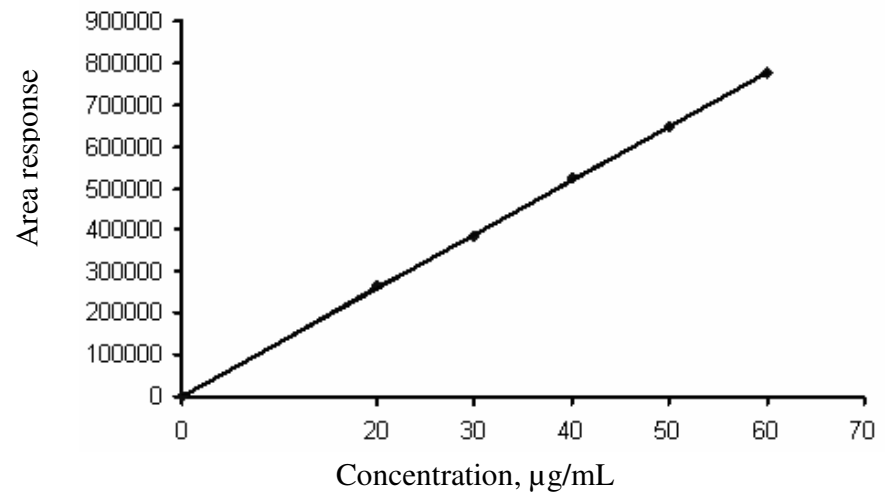

Figure 3. Calibration plot for aripiprazole.

\section{Limits of detection and quantification}

The limit of detection (LOD) is defined as the lowest concentration of an analyte that can be readily detected but not necessarily quantified. It is usually regarded as the amount for which the signal-to-noise ratio (SNR) is 3:1. The limit of quantitation (LOQ) is defined as the lowest concentration of an analyte that can be quantified with acceptable precision and accuracy. It is usually regarded as the amount for which the SNR is 10:1. Two types of solution, blank solution and solutions containing known, progressively decreasing concentrations of the analyte, were prepared and analyzed. LOD and LOQ were 0.411 and $1.248 \mu \mathrm{g} \mathrm{mL}^{-1}$, respectively.

Accuracy

Recovery studies were performed in triplicate after spiking raw material in volumetric flasks with amounts of aripiprazole equivalent to 80,100 and $120 \%$ of the standard concentration of aripiprazole $\left(40 \mu \mathrm{g} \mathrm{mL}^{-1}\right)$ as in the analytical method. The results obtained (Table 1) indicate that recovery were excellent, not less than $99 \%$ and that relative standard deviations also less than $2 \%$.

Table 1. Accuracy of the method.

\begin{tabular}{cccccc}
\hline Drug & $\begin{array}{c}\text { Spike } \\
\text { level, } \%\end{array}$ & $\begin{array}{c}\text { Concentration } \\
\text { added, } \mu \mathrm{mL}^{-1}\end{array}$ & $\begin{array}{c}\text { Mean amount } \\
\text { recovered, } \\
\mu \mathrm{g} \mathrm{mL}^{-1}, \mathrm{n}=3\end{array}$ & $\begin{array}{c}\text { Recovery, } \\
\%, n=3\end{array}$ & $\begin{array}{c}\mathrm{RSD}, \\
\%, n=3\end{array}$ \\
\hline Aripiprazole & 80 & 32 & 32.24 & 100.75 & 0.86 \\
tablets & 100 & 40 & 39.93 & 99.82 & 0.95 \\
& 120 & 48 & 48.02 & 100.04 & 0.97 \\
\hline
\end{tabular}

\section{Precision}

Intra-day precision was calculated from results obtained from five-fold replicate analysis of samples at three different concentrations on the same day. Inter-day precision was calculated from results from the same samples analyzed on five consecutive days. The results obtained are listed in Table 2. 
Table 2. Intra-day and inter-day precision of the method.

\begin{tabular}{|c|c|c|c|c|}
\hline \multirow[b]{2}{*}{$\begin{array}{l}\text { Concentration } \\
\text { Added, } \mu \mathrm{g} \mathrm{mL}^{-1}\end{array}$} & \multicolumn{2}{|c|}{ Intra-day precision } & \multicolumn{2}{|c|}{ Inter-day precision } \\
\hline & $\begin{array}{l}\text { Mean amount found, } \\
\mu \mathrm{g} \mathrm{mL} \mathrm{L}^{-1}, \mathrm{n}=5\end{array}$ & $\begin{array}{c}\text { RSD, } \\
\%, \mathrm{n}=5\end{array}$ & $\begin{array}{c}\text { Mean amount } \\
\text { Found, } \mu \mathrm{g} \mathrm{mL}^{-1}, \mathrm{n}=5\end{array}$ & $\begin{array}{c}\text { RSD, } \\
\%, \mathrm{n}=5\end{array}$ \\
\hline 32 & 32.04 & 0.98 & 32.61 & 0.99 \\
\hline 40 & 40.12 & 0.95 & 39.99 & 1.07 \\
\hline 48 & 47.98 & 1.01 & 48.12 & 0.96 \\
\hline
\end{tabular}

Specificity

The specificity of the method was tested by chromatographing a mixture of commonly used tablet excipients, for example starch, lactose and magnesium stearate (blank placebo) and comparing the chromatogram with that obtained from a mixture of drug and the same additives (placebo). The chromatograms obtained (Figures $4 \& 5$ ) showed separation of the analyte from the excipients was complete, i.e. there was no interference from the excipients under the chromatographic conditions used for the analysis.

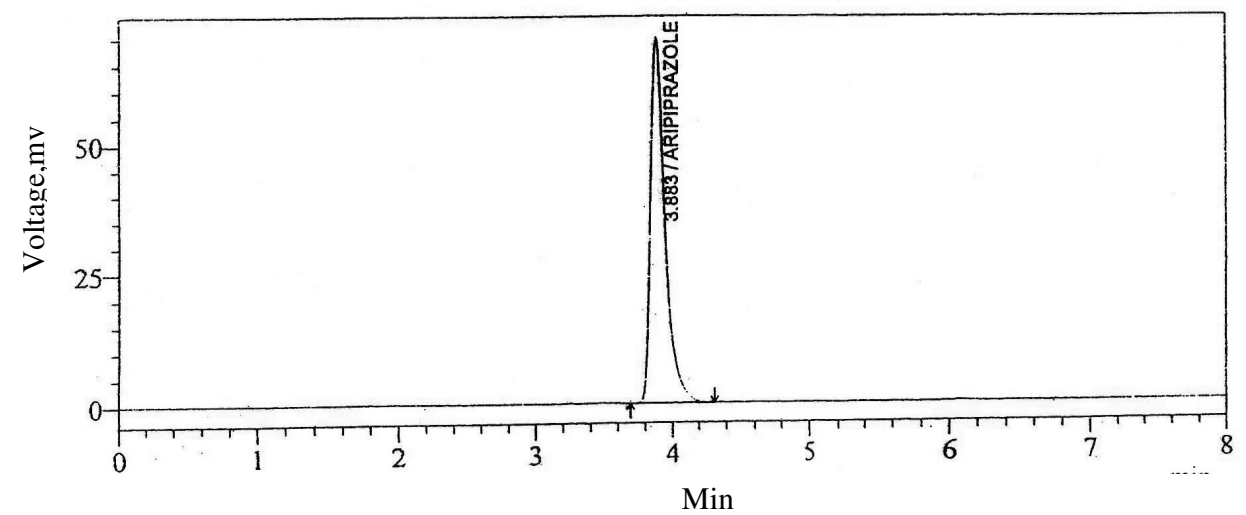

Figure 4. Chromatogram obtained from tablet sample.

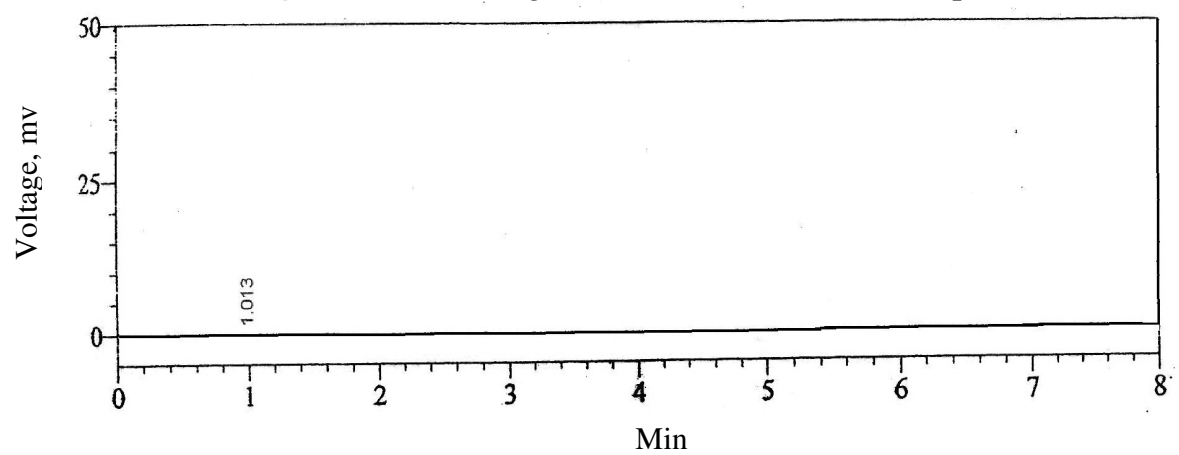

\section{Stability}

Figure 5. Chromatogram obtained from placebo.

The stability of aripiprazole in solution was checked by determining the percentage deviation of the amounts present in solution after $72 \mathrm{~h}$ at room temperature in comparison with the amount at zero time. The results obtained after $72 \mathrm{~h}$ showed no significant variation; the percentage deviation was less than $2 \%$ of the initial amount. This is indicative of good stability of each component in the mixture over a period of $72 \mathrm{~h}$. 


\section{Application of the method to tablets}

The method was used for determination of aripiprazole in a tablet formulation. The results obtained (Table 3) showed the amount found was that expected and RSD (\%) values were low, which confirms the method is suitable for routine analysis of the compound in pharmaceutical preparations. A typical chromatogram obtained from analysis of a tablet formulation is shown in Figure. 4.

Table 3. Results from analysis of aripiprazole in tablets.

\section{Conclusion}

\begin{tabular}{lc}
\hline Label claim. mg per tablet & 30 \\
\hline Amount found, mg per tablet & 29.98 \\
Amount found, $\%, \mathrm{n}=6$ & 99.93 \\
$\mathrm{RSD}, \%, \mathrm{n}=6$ & 0.021 \\
\hline
\end{tabular}

This RP-HPLC method for analysis of aripiprazole in formulations is very simple, sensitive, and accurate. The run time is 8 min only; so many samples can also be processed and analyzed in a short period of time. The procedure described is suitable for the routine estimation of aripiprazole in pharmaceutical formulations.

\section{References}

1. Kane J M, Carson W H, Saha A R, McQuade R D, Ingenito G G, Zimbroff D L and Ali M W, J Clin Psychiatry, 2002, 63, 763-71.

2. http://www.rxlist.com/aripiprazole.

3. Hui C H, Chin H L, Tsuo H L, Tsung M H, Hsien J C, Yu C W and Ying L T, $J$ Chromatogr B., 2007, 856, 57-61.

4. Masanori K, Yasuo M, Yukihiro H and Takahiko O, J Chromatogr B., 2005, 822, 294-299.

5. Frederique L, Kayssa D, Khalid T, Linda K, Sophie B, Pascal P and Marie L P, $J$ Chromatogr B, 2008, 867, 15-19.

6. Musenga A, Saracino M A, Spinelli D, Rizzato E, Boncompagni G, Kenndler E and Raggi M A, Anal Chim Acta, 2008, 612, 204-211.

7. Lancelin F, Djebrani K, Tabaouti K, Kraoul L, Brovedani S, Paubel P and Piketty M L, J Chromatogr B Analyt Technol Biomed Life Sci., 2008, 867, 15-9.

8. Shimokawa Y, Akiyama H, Kashiyama E, Koga T and Miyamoto G, J Chromatogr B Analyt Technol Biomed Life Sci., 2005, 821, 8-14.

9. Kirchherr H and Kühn-Velten W N, J Chromatogr B Analyt Technol Biomed Life Sci., 2006, 843, 100-113.

10. Li K Y, Zhou Y G, Ren H Y, Wang F, Zhang B K and Li H D, J Chromatogr B; Analyt Technol Biomed Life Sci., 2007, 850, 581-585.

11. Vjayakumar M and Muley P R, The Indian Pharmacist, 2005, 4, 71-75.

12. Snyder L R, Kirkland J J and J L Glajch (Eds) Practical HPLC Method Development, Wiley-Interscience, New York, 1988, 402.

13. International Conference on the Harmonization of Technical Requirements for the Registration of Pharmaceuticals for Human Use (ICH) Q2B. Validation of Analytical Procedures, Methodology, 1996, 1-8.

14. US Pharmacopoeial Convention, United States Pharmacopoeia, $28^{\text {th }}$ Edn, US Pharmacopoeial Convention, Rockville, MD, 2005,1196-1198.

15. FDA: Guidance for Industry, Analytical Procedures and Methods Validation, 2000. 


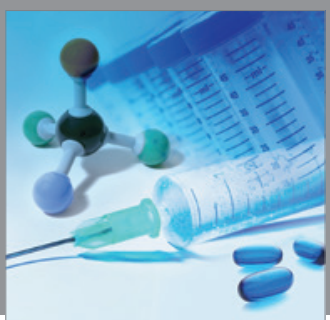

International Journal of

Medicinal Chemistry

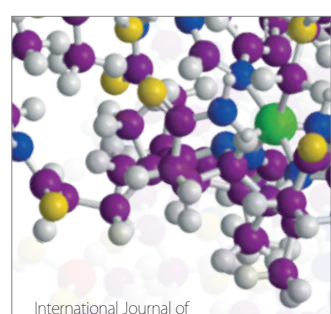

Carbohydrate Chemistry

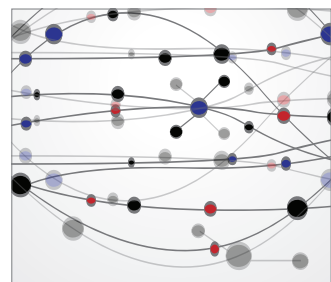

The Scientific World Journal
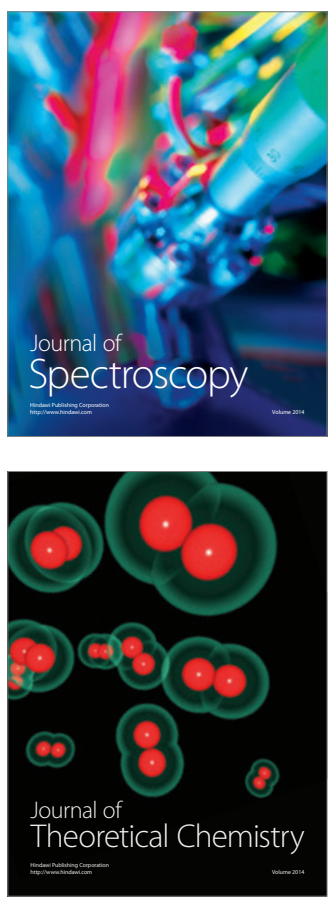
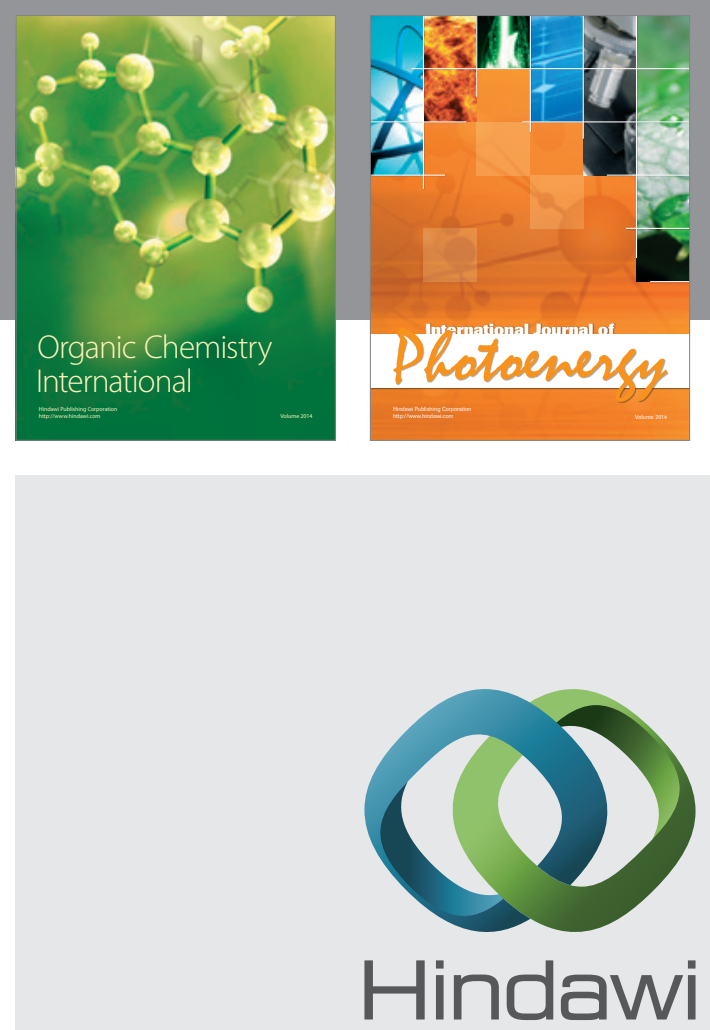

Submit your manuscripts at

http://www.hindawi.com
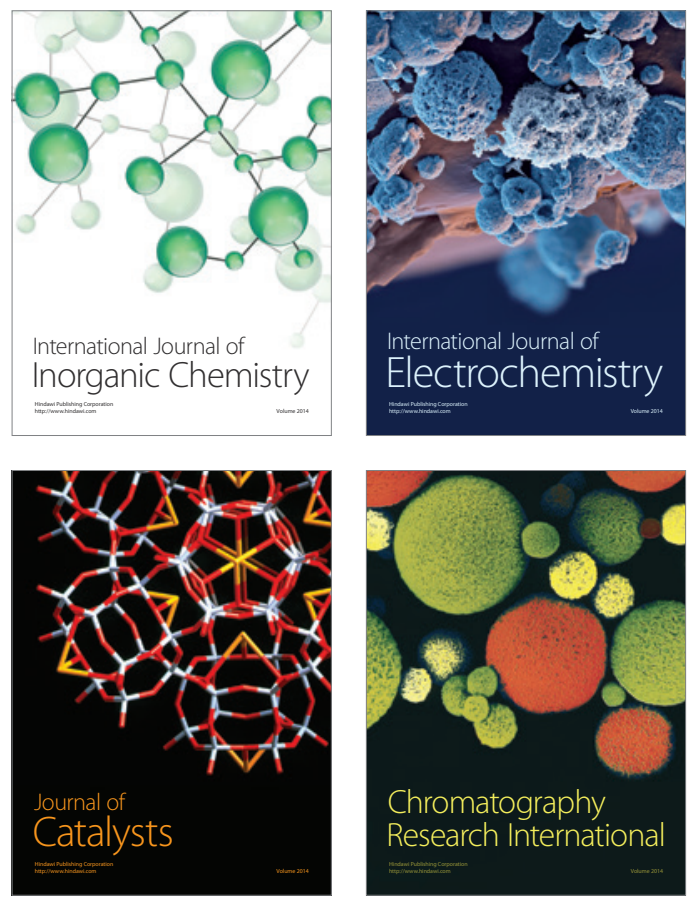
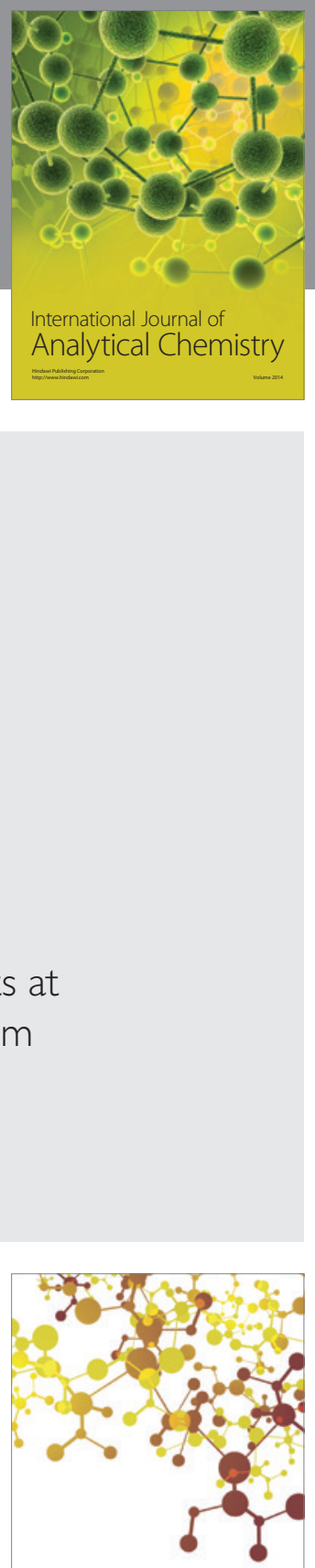

Journal of

Applied Chemistry
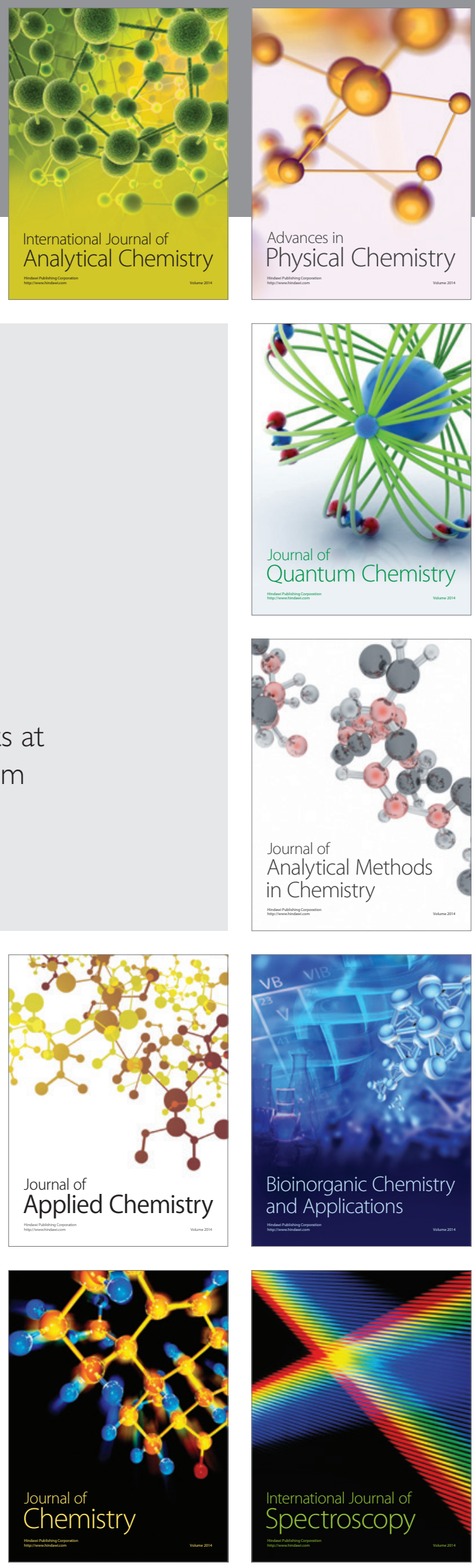